\title{
Late Cardiovascular Consequences of Gestational Diabetes Mellitus
}

\author{
Rhonda Bentley-Lewis, M.D., M.B.A., M.M.Sc. ${ }^{1,2}$ \\ ${ }^{1}$ Instructor in Medicine, Harvard Medical School, Boston, Massachusetts. \\ ${ }^{2}$ Associate Physician, Division of Endocrinology, Diabetes, and Hypertension, Department of \\ Medicine, Brigham and Women's Hospital, Boston, Massachuserts.
}

\begin{abstract}
Gestational diabetes mellitus (GDM), defined as carbohydrate intolerance of any degree first recognized during pregnancy, complicates $\sim 4 \%$ of all pregnancies in the United States. Several factors can increase one's risk of developing GDM, including obesity, family history of type 2 diabetes mellitus (T2DM), and race/ethnicity. Conversely, a history of GDM can increase the risk of developing not only T2DM but also cardiovascular disease (CVD) independent of a diagnosis of T2DM. Several investigations have explored GDM relationships with CVD risk factors, CVD surrogate markers, and clinically evident CVD. These studies have included evaluations of biochemical parameters, such as inflammatory and endothelial biomarkers; endothelial dysfunction, such as that seen in impaired brachial artery flow-mediated vasodilation; and vascular dysfunction, manifest as cardiac dysfunction or in diseases such as hypertension. This article will review these studies and examine factors considered to be responsible for promoting CVD in women with a history of GDM, such as T2DM and metabolic syndrome and its components. In addition, studies evidencing CVD in women with a history of GDM will be explored.
\end{abstract}

\section{Keywords}

Gestational diabetes mellitus; cardiovascular disease; endothelial dysfunction; inflammation; biomarkers

\begin{abstract}
Gestational diabetes mellitus (GDM), defined as carbohydrate intolerance of any degree first recognized during pregnancy, ${ }^{1}$ complicates $\sim 4 \%$ of all pregnancies in the United States with a prevalence of 1 to $14 \%$ and an annual incidence of more than 135,000 cases. ${ }^{1}$ Prevalence estimates of GDM vary depending on the population under examination, and several studies report that the prevalence of GDM is higher among racial/ethnic minorities compared with that among non-Hispanic white populations. ${ }^{2-5}$ One population study reported that the age-adjusted prevalence of GDM per 100 births in 2005 was $4.9 \%$ among non-Hispanic whites and 5.2\% among non-Hispanic blacks. ${ }^{4}$ Additionally, the increasing
\end{abstract}

Copyright (C 2009 by Thieme Medical Publishers, Inc.

Address for correspondence and reprint requests; Rhonda Bentley-Lewis M.D., M.B.A., M.M.Sc., Associate Physician, Brigham and Women's Hospital, Department of Medicine, Division of Endocrinology, Diabetes, and Hypertension, 221 Longwood Avenue, Boston, MA 02115 (rbentleylewis@ partners.org).. 
prevalence among ethnic minorities of risk factors associated with the development of GDM, such as obesity ${ }^{6}$ suggests that the racial disparity in GDM prevalence will persist.

There are several factors that can increase the risk of developing GDM, including obesity, ${ }^{7}$ family history of type 2 diabetes mellitus (T2DM),${ }^{8}$ and race/ethnicity. ${ }^{8}$ Notably, features that increase the risk of developing GDM, including obesity and the metabolic syndrome components, are also associated with an increased risk of developing cardiovascular disease (CVD). ${ }^{9}$ Normoglycemic pregnancy presents a metabolic stress characterized by insulin resistance with postprandial hyperglycemia; dyslipidemia with increased triglycerides and low-density lipoprotein (LDL); and increased inflammation including elevated C-reactive protein (CRP) and plasminogen activator inhibitor-1 (PAl-1). ${ }^{10}$ Therefore, the stress imposed by GDM on an already compromised metabolic state can potentially convert a usually transient metabolic derangement into a more permanent abnormality that will increase the likelihood ofCVD development. This review will examine investigations of GDM with respect to CVD risk factors, such as T2DM; CVD surrogate measures, such as endothelial dysfunction; and diagnosed CVD, such as coronary artery disease (Table 1).

\section{CARDIOVASCULAR DISEASE RISK FACTORS}

\section{Type 2 Diabetes Mellitus}

Type 2 diabetes mellitus has been considered a CVD risk equivalent, ${ }^{11}$ and it is well established that GDM increases the risk for the development of T2DM. ${ }^{12}$ Di Cianni et a ${ }^{13}$ showed that women who underwent an oral glucose tolerance test (OGTT) 2 years after a GDM pregnancy, then classified as having diabetes, impaired glucose tolerance (IGT), or normal glucose tolerance, demonstrated significantly impaired insulin sensitivity and increased insulin resistance compared with women with prior normal pregnancy. Several investigations have shown that women with a history of GDM have a 17 to $63 \%$ risk of developing T2DM within the 5 to 16 years after the GDM pregnancy. ${ }^{14,15}$ Studies have also demonstrated that the rate of conversion from GDM to postpartum T2DM differs based on characteristics such as the ethnicity of the women and insulin use during pregnancy. ${ }^{16}$

\section{Blood Pressure}

High blood pressure is a well-established modifiable risk factor for coronary heart disease. ${ }^{17}$ High blood pressure during pregnancy, as seen in gestational hyper-tension ${ }^{18}$ or preeclampsia, ${ }^{19}$ has been associated with insulin resistance. In fact, women with higher glucose and insulin levels are more likely to develop preeclampsia, ${ }^{20}$ and women with a history of preeclampsia have greater insulin resistance ${ }^{21}$ and an increased incidence of hypertension when studied several years after delivery. ${ }^{22}$ Additionally, one study of women 2 to 5 years after a pregnancy complicated by GDM found that these women had higher systolic blood pressures than that of women With normoglycemic pregnancies. ${ }^{23}$ Moreover, beyond the relationships among hyperglycemia, hyperinsulinemia, and hypertension, a diagnosis of G DM has also been associated with increased blood pressure. ${ }^{10}$

Bryson et $\mathrm{al}^{24}$ examined the relationship between GDM and hypertension by conducting a case-control analysis of birth records of mothers delivering infants in Washington state between 1992 and 1998. Diagnoses of pregnancy-induced hypertension (PIH) were 
identified by International Classification of Diseases, Ninth Revision (ICD-9), codes and divided into populations with gestational hypertension $(n=8943)$, mild preeclampsia $(n=$ 5468), severe preeclampsia $(n=1180)$, and eclampsia $(n=154)$. Gestational diabetes was also identified by ICD-9 code, and a control population $(n=47,237)$ was selected by random sampling. The women with PIH were younger, had lower body mass index (BMI), were more often primigravid, and had more prenatal care compared with those of the control women. The data revealed that, after adjusting for BMI, age, race/ethnicity, parity, and adequate prenatal care, GDM was significantly associated with mild and severe preeclampsia as well as gestational hypertension with odds ratios (ORs) of 1.50, 1.53, and 1.40 , respectively. Of note, after the same statistical adjustments previously noted, white mothers with gestational diabetes had a 1.3 to 1.5 greater risk of falling into one of the PIH categories, whereas black mothers had a 3- to 4-fold greater risk of PIH compared with that of their racially matched controls. Although this study is limited by its use of administrative data to derive its populations, a Swedish study using similar methods also found a significantly increased risk of preeclampsia (OR, 3.16; 95\% CI [1.65, 6.03]) and insignificantly increased risk of gestational hypertension (OR, 1.34; 95\% CI [0.49, 3.71]) among women with GDM. ${ }^{25}$

A study using actual measurements of blood pressure has also examined the link between GDM and blood pressure. Noninvasive ambulatory arterial pressure monitoring (AAPM) has been performed reliably during pregnancy and found to be highly correlated with endorgan damage and left ventricular hypertrophy. ${ }^{26}$ Oren et $\mathrm{al}^{27}$ performed AAPM on women in the third trimester of pregnancy who were normotensive, hypertensive, or had GDM. There were 10 women in each group at similar gestational ages, but the GDM women were significantly older and slightly more over-weight than the women of other two groups. All of the women maintained a normal reduction in mean arterial pressure during the night; however, the decrease in blood pressure was less in the GDM group than that in the normotensive group ( $8 \mathrm{~mm} \mathrm{Hg}$ vs. $12 \mathrm{~mm} \mathrm{Hg} ; p=\mathrm{NS}$ ) and the heart rate of the GDM women was significantly greater than that of the other two groups (75 \pm 6.4 vs. $64 \pm 2.6$; $p<$ $0.001)$.

\section{Lipid Profile}

An uncomplicated pregnancy is notable for a lipid profile that promotes CVD risk, characterized by increased triglycerides and small, dense LDL particles. ${ }^{28}$ In addition, glucose intolerance, either T2DM or GDM, augments the atherogenicity of the lipid profile. In women with a history of GDM, there is a significant difference in postpartum fasting lipid levels in these women compared with those of women who had normoglycemic pregnancies. ${ }^{29}$ Meyers-Seifer and Vohr studied 56 women after a pregnancy complicated by GDM and 48 women after a normoglycemic pregnancy. ${ }^{29}$ These women were all within 5 to 6 years postpartum and underwent metabolic, anthropometric, and hemodynamic assessments. The two groups did not differ based on age, BMI, or socioeconomic status; however, more women with GDM had a family history of T2DM compared with that of the controls ( $40 \%$ vs. $15 \%$; $p=0.008$ ). Total cholesterol, triglyceride, and LDLcholesterollevels were significantly higher in the women with GDM compared with that in the controls, whereas the high-density lipoprotein (HDL)-cholesterol did not differ between 
the two groups. In addition, systolic blood pressure was also higher among the women with a history of GDM. In fact, elevated triglyceride levels correlated with BMI, insulin, and systolic blood pressure p; 1ramctcrs, whereas HDL-cholesterol correlated inversely with insulin levels in the GDM women only, evidencing a clustering of these metabolic abnormalities in the GDM population similar to that seen $\mathrm{m}$ the metabolic syndrome.

\section{Metabolic Syndrome}

Metabolic syndrome has been observed to be more prevalent among women with a history of GDM than among women without GDM. ${ }^{30,31}$ A study of young, obese, premenopausal women revealed that those with a history of GDM were more likely to have the metabolic syndrome than were those without a GDM history $(86.6 \%$ vs. $73.5 \% ; p<0.001) .{ }^{32}$ This increased prevalence has been attributed to various causes, including an increased frequency of abdominal obesity and lower HDL levels, or to GDM unmasking prepregnancy metabolic syndrome. ${ }^{33}$

Data from an examination of the National Health and Nutrition Examination Survey III revealed that women with a history of GDM $(n=85)$ had similar cardiovascular risk factor profiles, including blood pressure and lipid parameters, compared with that of women with a pregnancy history free of diabetes $(n=4328) .{ }^{34}$ However, the absolute number of metabolic syndrome characteristics was indeed greater among women with a history of GDM compared with that among the unaffected women. Additionally, this population of women with a history of GDM was relatively small, and the authors note that it may have represented a relatively healthier population of women compared with the women with GDM histories who developed T2DM who were not included in the study.

\section{CARDIOVASCULAR DISEASE SURROGATE MEASURES}

\section{Endothelial Dysfunction}

The endothelium, the largest endocrine organ, ${ }^{35}$ secretes vasoactive substances, such as vasodilators like nitric oxide and vasoconstrictors like angiotensin, that exert counterbalancing forces on the vasculature. ${ }^{36,37}$ VasCular disease represents an imbalance in these forces leading to increased vasoconstriction, inflammation, and, ultimately, impaired endothelial function. Risk factors for CVD, such as smoking, obesity, hypertension, and diabetes, impair endothelial function. ${ }^{36,38,38,39}$ The severity of endothelial dysfunction has been associated with the risk for an initial or recurrent cardiovascular event, ${ }^{40-43}$ and medical and lifestyle interventions that reduce CVD risk have been associated with improved endothelial function. ${ }^{44,45}$ Therefore, identifYing endothelial dysfunction would be valuable because this represents preclinical CVD that could benefit from primary prevention efforts.

Assessment of endothelial function reflected in nitric oxide synthesis derangements has been evaluated both during and after pregnancy complicated by GDM. During pregnancy, an investigation of brachial artery flow-mediated dilation (FMD), a technique strongly correlated with the invasive assessment of endothelial function in coronary arteries ${ }^{46}$ was performed in a population of pregnant women grouped as 15 normoglycemic, 10 IGT, and 
13 GDM. This study revealed that the women with IGT had FMD at $70 \%$ of the control group's FMD, and the GDM groups' FMD was only $38 \%$ that of the controls. ${ }^{47}$

After delivery, vascular dysfunction has been examined in women with a history of GDM. One Swedish study revealed increased common carotid artery stiffness and impaired extremity acetylcholine-induced vasodilation in 17 women 2 to 4 years after GDM delivery compared with that in 20 women with normal pregnancy histories. ${ }^{48}$ Another study observed impaired FMD among women with a history of GDM, and significantly decreased nitrate-induced dilation in the obese post-GDM women, compared with that in women after normal pregnancies studied 3 to 6 months after delivery and segregated by BMI $<27$ ( $n=$ 17) and BMI $\geq 27(n=16) .{ }^{45}$

Another measure of vascular function is carotid intimal-medial thickness (CIMT). CIMT has been known to be a marker of preclinical atherosclerosis ${ }^{49}$ and is commonly used as a surrogate of vascular disease morbidity and mortality. ${ }^{50} \mathrm{CIMT}$ has also been shown to be predictive of CVD in T2DM ${ }^{51}$ and found to regress in cases of improved glycemia in T2DM..$^{52}$ Tarim et al ${ }^{53}$ studied 30 women with GDM and 40 normoglycemic women of similar age and BMI in the second trimester of pregnancy. They observed that CIMT was significantly greater among the women with GDM compared with that among the non-GDM women $(0.582 \pm 0.066 *$ mm vs. $0.543 \pm 0.049 \mathrm{rom} ; p=0.006)$; however, no studies were performed post-partum to determine if these differences resolved with resolution of the GDM.

Another study of CIMT in women with a history of GDM involved 28 women with and 24 women without a history of GDM 2 years after delivery. ${ }^{23}$ The women with a history of GDM were significantly older, had higher blood pressure (although still within normal range) and waist circumference (although similar BMis) compared with that of the women with normoglycemic pregnancy histories. Although the postpartum OGTI revealed that nine of the women post-GDM had impaired glucose tolerance and/ or impaired fasting glucose, none had diabetes. The mean common CIMT was greater among the women with prior GDM compared with that of controls $(0.57 \pm 0.058 \mathrm{~mm}$ vs. $0.51 \pm 0.051 \mathrm{~mm} ; p<0.01)$.

Two additional investigations of CIMT were performed by Xiang in the setting of a thiazolidinedione intervention. The Troglitazone in the Prevention of Diabetes (TRJPOD) study examined the use of troglitazone or placebo in obese Hispanic women with a previous history of GDM. ${ }^{54}$ Among the women who had follow-up CIMT measured, there were no baseline differences between those who received troglitazonc $(n=93)$ and 'those who received placebo $(n=99)$, including BMI, blood pressure, lipids, and glucose tolerance. However, the authors observed that the average rate of change of CIMT was $31 \%$ lower in the troglita-zone group $\left(6.5 \times 10^{-3} \mathrm{mrnly}\right)$ that than that in the placebo group $(9.4 \times$ $10-{ }^{3} \mathrm{mmly} ; \mathrm{p}=0.05$ ). Of note, there was also a $55 \%$ risk reduction in progression to T2DM in women who received troglitazone when compared with that of those who received placebo.

The Pioglitazone in Prevention of Diabetes (PIPOD) study ${ }^{55}$ enrolled women who had completed TRJPOD without developing T2DM. These women were randomly assigned to receive either pioglitazone or placebo for a period of 3 years; there were 31 women who 
entered the study after troglitazone and 30 women who had received placebo. Mter treatment with pioglitazone, the CIMT progression rate was $69 \%$ lower in the women who had initially received placebo $(0.0031 \mathrm{~mm} / \mathrm{y}$ vs. $0.010 \mathrm{mmly} ; p=0.006)$ and $38 \%$ lower in the women who had received troglitazone ( $0.0037 \mathrm{mmly}$ vs. $0.0060 \mathrm{mmly} ; \mathrm{p}=0.26)$. Of note, a $4.6 \%$ yearly incidence rate of T2DM was reported in the pioglitawne group compared with $12.1 \%$ in the placebo group.

\section{Biochemical Markers}

Several biochemical parameters have been examined with respect to GDM, including asymmetric dimethylargimne ${ }^{56,57}$ and measurements of nitric oxide production. ${ }^{58}$ Insulin resistance is also associated with endothelial dysfunction through alterations in nitric oxide. Insulin stimulation of nitric oxide production via increased nitric oxide synthase activity is associated with increased endothelium-dependent vasodilation in healthy individuals. However, in those who manifest insulin resistance, this nitric oxide--mediated vasodilation is decreased. ${ }^{59}$ Pharmacologic interventions that improve insulin resistance have also been shown to improve endothelium-dependent vasodilation. ${ }^{60,61}$ Additionally, insulin resistance is associated with increased levels of free fatty acids, which can in turn decrease nitric oxide synthase activity and reduce nitric oxide production in insulin resistance. ${ }^{62}$

Biochemical markers of endothelial dysfunction have also been investigated in GDM populations. A small population study by Kautzky-Willer et al demonstrated that E-selectin and vascular adhesion molecule-1 (VCAM-1) were elevated in women after a GDM pregnancy compared with that in women after a normal pregnancy, whereas intercellular adhesion molecule-1 (ICAM-1) did not differ between the two groups. ${ }^{63}$ A larger study found elevations in ICAM-1 and E-selectin in the women studied within 6.5 years after GDM pregnancy, but observed no differences in VCAM-1 levels. ${ }^{64}$

Markers of inflammation have also been shown to be elevated In GDM compared with that in women with a norm al pregnancy h1story. ${ }^{10,30} \mathrm{C}$-reactive protem (CRP), ${ }^{65-67}$ fibrinogen, ${ }^{66}$ and plasminogen activator inhibitor- ${ }^{65}$ were observed to be elevated or specifically associated with GDM populations. Additionally, a prospective study of women from the second trimester until after delivery revealed an elevated CRP association with increased risk for developing GDM, even after adjusting for maternal prepregnancy BM1, ${ }^{67}$ contrary to a prior report. ${ }^{68}$

\section{Autonomic Dysfunction}

Gasic et al ${ }^{69}$ studied cardiac autonomic dysfunction as revealed through alterations in heart rate variability. He performed 24-hour Holter monitoring on 48 healthy women with a history of GDM and assessed heart rate variability in both low-frequency as well as highfrequency domains. The investigators observed that $52 \%$ of women with a history ofGDM in the prior $1.0 \pm 0.3$ years were found to have sympathetic and parasympathetic autonomic neuropathy reflected in reductions of lowand high-frequency power spectral densities, respectively. An earlier study of autonomic dysfunction in women with an 8-year history ofGDM also revealed both parasympathetic and sympathetic autonomic neuropathy, but this population included women who had diabetes or glucose intolerance at the time of study? ${ }^{70}$ 


\section{CARDIOVASCULAR DISEASE .MANIFESTATIONS}

\section{Coronary Artery Disease and Cardiovascular Events}

Given this significant impact of T2DM on the risk for developing CVD, Carr et al ${ }^{32}$ examined a population of women from the Genetics of Non-Insulin Dependent Diabetes Study ${ }^{71}$ who had a first-degree relative with T2DM. The women were divided into two groups: those who had a history of GDM $(n=332)$ and those who did not $(n=662)$. The women were all similarly obese, but the women with GDM were younger and more often premenopausal than the controls. Nonetheless, the OR of self-reported CVD, defined as coronary artery disease (CAD) and/or stroke, was greater among the GDM women than among the controls, even after adjusting for age and menopausal status (OR, $1.85 ; 95 \% \mathrm{Cl}$ [1.21 to 2.82]). Moreover, the similarly adjusted OR of CAD was higher among women with a GDM history (OR, 1.58; $95 \% \mathrm{Cl}$ [1.00 to 2.49]) and was diagnosed at an earlier age than CAD among the women with no GDM history ( $45.5 \pm 2.2$ years vs. $52.5 \pm 1.9$ years; $p=0.02$ ).

Additionally, the increased OR for CVD remained even after adjusting for metabolic syndrome (OR, 1.74; 95\% $\mathrm{Cl}$ [1.10 to 2.76]) orT2DM (OR, 1.56; 95\% Cl [1.00 to 2.43]). Although this study is limited by the self-reporting of GDM and CVD history, it does provide intriguing evidence that GDM may confer additional CVD risk above and beyond the CVD risk associated with obesity, the metabolic syndrome, and T2DM.

Another investigation ofCVD events after GDM was performed by Shah et al, ${ }^{72}$ who conducted a retrospective matched-cohort study of an administrative database of a Canadian population including 8191 women with a history of GDM and 81,262 controls followed for a median of 11.5 years, and the authors observed a hazard ratio of 1.71 (95\% $\mathrm{Cl}$ [1.08 to 2.9]) for CVD including CAD events that decreased to 1.13 (95\% $\mathrm{Cl}$ [0.67 to 1.89]) after adjusting for the development of T2DM. Although CVD risk was more attributable to $\mathrm{T} 2 \mathrm{DM}$ in this cohort, the hazard ratio is in the range reported by Carr et al? ${ }^{32}$

\section{Cardiac Dysfunction}

Cardiac dysfunction resulting from GDM has been examined in the setting of diastolic dysfunction in a study of 13 women with GDM and 13 normoglycemic women studied during the third trimester and again 2 months after delivery. ${ }^{73}$ The women with GDM were noted to have significantly decreased rapid filling to late filling time ratios both during and after pregnancy. In addition, tissue Doppler parameters revealed a lower lateral mitral annulus early diastolic velocity (Em), lower Em/lateral mitral annulus early diastolic velocity (Am), and higher Am that remained postpartum. These data suggest that these women with GDM, whose mean age was only $30.2 \pm 5.9$ years, manifested evidence of diastolic dysfunction not observed among the control women. However, this study was not designed to determine if these tissue Doppler abnormalities were associated with overt CVD.

Oren et $\mathrm{al}^{27}$ also performed two-dimensional M-mode echocardiography on women in the third trimester of pregnancy who were normotensive, hypertensive, or had GDM. The echocardiograms revealed the GDM women had a significantly greater left ventricular mass 
compared with that of the hypertensive and the normotensive women, primarily due to left ventricular dilatation rather than septal or posterior wall thickness. The GDM and hypertensive women also had impaired left ventricular relaxation but maintained normal ejection fraction and cardiac output.

\section{CONCLUSIONS}

GDM represents a significant risk factor for the development of CVD in women; both patients and physicians need to be aware of not only intrapartum but also postpartum and lifetime risks. An initial focus of CVD risk management for this population of women should be on reducing the risk of progression to T2DM postpartum, as well as efforts to minimize modifiable CVD risk factors, including blood pressure, abdominal adiposity, and dyslipidemia. Ideally, these efforts will incorporate both prenatal and postpartum education about risk awareness, healthy lifestyle behaviors, breast-feeding, and potential pharmacotherapy options. ${ }^{74}$ Future investigations may address how best to use information regarding biochemical and subclinical CVD evidenced in clinical investigations in primary prevention endeavors.

\section{Acknowledgments}

This work was supported in part by NIH grant K23RR0233333 and Harvard Medical School Eleanor and Miles Shore 50th Anniversary Fellowships for Scholars in Medicine both awarded to R.B-L. The author thanks Ffyona Patel, BA, for assistance with the literature review.

\section{REFERENCES}

1. American Diabetes Association. Diagnosis and classification of diabetes mellitus. Diabetes Care. 2006; 29(Suppl 1):S43-S48. [PubMed: 16373932]

2. Berkowitz GS, Lapinski RH, Wein R, Lee D. Race/ethnicity and other risk factors for gestational diabetes. Am J Epidemiol. 1992; 135:965-973. [PubMed: 1595695]

3. Dabelea D, Snell-Bergeon JK, Hartsfield CL, Bischoff KJ, Hamman RF, McDuffie RS. Kaiser Permanente of Colorado GDM Screening Program. Increasing prevalence of gestational diabetes mellitus (bDM) over time and by birth cohort: Kaiser Permanente of Colorado GDM Screening Program. Diabetes Care. 2005; 28:579-584. [PubMed: 15735191]

4. Getahun D, Nath C, Ananth CV, Chavez MR, Smulian JC. Gestational diabetes in the United States: temporal trends 1989 through 2004. Am J Obstet Gynecol. 2008; 198:525, e1-5. [PubMed: 18279822]

5. Lawrence JM, Contreras R, Chen W, Sacks DA. Trends in the prevalence of pre-existing diabetes and gestational diabetes mellitus among a racially/ethnically diverse population of pregnant women, 1999-2005. Diabetes Care. 2008; 31:899-904. [PubMed: 18223030]

6. Ogden CL, Carroll MD, Curtin LR, McDowell MA, Tabak CJ, Flegal KM. Prevalence of overweight and obesity in the United States, 1999-2004. JAMA. 2006; 295:1549-1555. [PubMed: 16595758]

7. Lu GC, Rouse DJ, DuBard M, Cliver S, Kimberlin D, Hauth JC. The effect of the increasing prevalence of maternal obesity on perinatal morbidity. Am J Obstet Gynecol. 2001; 185:845-849. [PubMed: 11641663]

8. Rosenberg TJ, Garbers S, Lipkind H, Chiasson MA. Maternal obesity and diabetes as risk factors for adverse pregnancy outcomes: differences among 4 racial/ethnic groups. Am J Public Health. 2005; 95:1545-1551. [PubMed: 16118366] 
9. Verma A, Boney CM, Tucker R, Vohr BR. Insulin resistance syndrome in women with prior history of gestational diabetes mellitus. J Clin Endocrinol Metab. 2002; 87:3227-3235. [PubMed: 12107230]

10. Carpenter MW. Gestational diabetes, pregnancy hypertension, and late vascular disease. Diabetes Care. 2007; 30(Suppl 2):S246-S250. [PubMed: 17596480]

11. Haffner SM, Lehto S, Rönnemaa T, Pyörälä K, Laakso M. Mortality from coronary heart disease in subjects with type 2 diabetes and in nondiabetic subjects with and without prior myocardial infarction. N Engl J Med. 1998; 339:229-234. [PubMed: 9673301]

12. Mokdad AH, Ford ES, Bowman BA, et al. Prevalence of obesity, diabetes, and obesity-related health risk factors, 2001. JAMA. 2003; 289:76-79. [PubMed: 12503980]

13. Di Cianni G, Miccoli R, Volpe L, Lencioni C, Del Prato S. Intermediate metabolism in normal pregnancy and in gestational diabetes. Diabetes Metab Res Rev. 2003; 19:259-270. [PubMed: 12879403]

14. Coustan DR, Carpenter MW, O'Sullivan PS, Carr SR. Gestational diabetes: predictors of subsequent disordered glucose metabolism. Am J Obstet Gynecol1993. 168:1139-1144. discussion 1144-1145.

15. Kjos SL, Peters RK, Xiang A, Henry OA, Montoro M, Buchanan TA. Predicting future diabetes in Latino women with gestational diabetes. Utility of early postpartum glucose tolerance testing. Diabetes. 1995; 44:586-591. [PubMed: 7729620]

16. Kim C, Newton KM, Knopp RH. Gestational diabetes and the incidence of type 2 diabetes: a systematic review. Diabetes Care. 2002; 25:1862-1868. [PubMed: 12351492]

17. Lloyd-Jones D, Adams R, Carnethon M, et al. American Heart Association Statistics Committee and Stroke Statistics Subcommittee. Heart disease and stroke statistics-2009 update: a report from the American Heart Association Statistics Committee and Stroke Statistics Subcommittee. Circulation. 2009; 119:e21-e181. [PubMed: 19075105]

18. Yasuhi I, Hogan JW, Carnick J, Sosa MB, Carpenter MW. Midpregnancy serum C-peptide concentration and subsequent pregnancy-induced hypertension. Diabetes Care. 2001; 24:743-747. [PubMed: 11315841]

19. Wolf M, Sandler L, Munõz K, Hsu K, Ecker JL, Thadhani R. First trimester insulin resistance and subsequent pree-clampsia: a prospective study. J Clin Endocrinol Metab. 2002; 87:1563-1568. [PubMed: 11932283]

20. Solomon CG, Seely EW. Hypertension in pregnancy. Endocrinol Metab Clin North Am. 2006; 35:157-171, vii. [PubMed: 16310647]

21. Laivuori H, Tikkanen MJ, Ylikorkala 0. Hyperinsulinemia 17 years after preeclamptic first pregnancy. J Clin Endocrinol Metab. 1996; 81:2908-2911. [PubMed: 8768850]

22. Sibai BM, el-Nazer A, Gonzalez-Ruiz A. Severe preeclampsia-eclampsia in young primigravid women: subsequent pregnancy outcome and remote prognosis. Am J Obstet Gynecol. 1986; 155:1011-1016. [PubMed: 3777042]

23. Volpe L, Cuccuru I, Lencioni C, et al. Early subclinical atherosclerosis in women with previous gestational diabetes mellitus. Diabetes Care. 2008; 31:e32. [PubMed: 18445712]

24. Bryson CL, Ioannou GN, Rulyak SJ, Critchlow C. Association between gestational diabetes and pregnancy-induced hypertension. Am J Epidemiol. 2003; 158:1148-1153. [PubMed: 14652299]

25. Ros HS, Cnattingius S, Lipworth L. Comparison of risk factors for preeclampsia and gestational hypertension in a population-based cohort study. Am J Epidemiol. 1998; 147:1062-1070. [PubMed: 9620050]

26. Perloff D, Sokolow M, Cowan R. The prognostic value of ambulatory blood pressures. JAMA. 1983; 249:2792-2798. [PubMed: 6842787]

27. Oren S, Golzman B, Reitblatt T, Turkot S, Kogan J, Segal S. Gestational diabetes mellitus and hypertension in pregnancy: hemodynamics and diurnal arterial pressure profile. J Hum Hypertens. 1996; 10:505-509. [PubMed: 8895033]

28. Toescu V, Nuttall SL, Kendall MJ, Martin U, Dunne F. Women with gestational diabetes should be targeted to reduce cardiovascular risk. BMJ. 2002; 325:966. [PubMed: 12399355]

29. Meyers-Seifer CH, Vohr BR. Lipid levels in former gestational diabetic mothers. Diabetes Care. 1996; 19:1351-1356. [PubMed: 8941463] 
30. Di Cianni G, Lencioni C, Volpe L, et al. C-reactive protein and metabolic syndrome in women with previous gestational diabetes. Diabetes Metab Res Rev. 2007; 23:135-140. [PubMed: 16770838]

31. Lauenborg J, Mathiesen E, Hansen T, et al. The prevalence of the metabolic syndrome in a Danish population of women with previous gestational diabetes mellitus is three-fold higher than in the general population. J Clin Endocrinol Metab. 2005; 90:4004-4010. [PubMed: 15840755]

32. Carr DB, Utzschneider KM, Hull RL, et al. Gestational diabetes mellitus increases the risk of cardiovascular disease in women with a family history of type 2 diabetes. Diabetes Care. 2006; 29:2078-2083. [PubMed: 16936156]

33. Noussitou P, Monbaron D, Vial Y, Gaillard RC. Ruiz J Gestational diabetes mellitus and the risk of metabolic syndrome: a population-based study in Lausanne, Switzerland. Diabetes Metab. 2005; 31(4 Pt 1):361-369. [PubMed: 16369198]

34. Kim C, Cheng YJ, Beckles GL. Cardiovascular disease risk profiles in women with histories of gestational diabetes but without current diabetes. Obstet Gynecol. 2008; 112:875-883. [PubMed: 18827131]

35. Zouboulis CC. Human skin: an independent peripheral endocrine organ. Horm Res. 2000; 54:230242. [PubMed: 11595811]

36. Calles-Escandon J, Cipolla M. Diabetes and endothelial dysfunction: a clinical perspective. Endocr Rev. 2001; 22:36-52. [PubMed: 11159815]

37. Widlansky ME, Gokce N, Keaney JF Jr, Vita JA. The clinical implications of endothelial dysfunction. J Am Coil Cardiol. 2003; 42:1149-1160.

38. Celermajer DS, Sorensen KE, Gooch VM, et al. Noninvasive detection of endothelial dysfunction in children and adults at risk of atherosclerosis. Lancet. 1992; 340:1, 111-1115. [PubMed: 1351599]

39. Steinberg HO, Chaker H, Learning R, Johnson A, Brechtel G, Baron AD. Obesity/insulin resistance is associated with endothelial dysfunction. Implications for the syndrome of insulin resistance. J Clin Invest. 1996; 97:2601-2610. [PubMed: 8647954]

40. Gokce N, Keaney JF Jr, Hunter LM, et al. Predictive value of noninvasively determined endothelial dysfunction for long-term cardiovascular events in patients with peripheral vascular disease. J Am Coil Cardial. 2003; 41:1769-1775.

41. Gokce N, Keaney JF Jr, Hunter LM, Watkins MT, Menzoian JO, Vita JA. Risk stratification for postoperative cardiovascular events via noninvasive assessment of endothelial function: a prospective study. Circulation. 2002; 105:1567-1572. [PubMed: 11927524]

42. Perticone F, Ceravolo R, Pujia A, et al. Prognostic significance of endothelial dysfunction in hypertensive patients. Circulation. 2001; 104:191-196. [PubMed: 11447085]

43. Heitzer T, Schlinzig T, Krohn K, Meinertz T, Miinzel T. Endothelial dysfunction, oxidative stress, and risk of cardiovascular events in patients with coronary artery disease. Circulation. 2001; 104:2673-2678. [PubMed: 11723017]

44. Kousta E, Efstathiadou Z, Lawrence NJ, et al. The impact of ethnicity on glucose regulation and the metabolic syndrome following gestational diabetes. Diabetologia. 2006; 49:36-40. [PubMed: 16341688]

45. Anastasiou E, Lekakis JP, Alevizaki M, et al. Impaired endothelium-dependent vasodilatation in women with previous gestational diabetes. Diabetes Care. 1998; 21:2111-2115. [PubMed: 9839102]

46. Anderson TJ, Uehata A, Gerhard MD, et al. Close relation of endothelial function in the human coronary and peripheral circulations. JAm Coil Cardiol. 1995; 26:1235-1241.

47. Paradisi G, Biaggi A, Ferrazzani S, DeCarolis S, Caruso A. Abnormal carbohydrate metabolism during pregnancy: association with endothelial dysfunction. Diabetes Care. 2002; 25:560-564. [PubMed: 11874947]

48. Hu J, Norman M, Wallensteen M, Gennser G. Increased large arterial stiffness and impaired acetylcholine induced skin vasodilatation in women with previous gestational diabetes mellitus. $\mathrm{Br}$ J Obstet Gynaecol. 1998; 105:1279-1287. [PubMed: 9883919] 
49. Bats ML, deJong PT, Hofman A, Grobbee DE. Left, right, near or far wall common carotid intimamedia thickness measurements: associations with cardiovascular disease and lower extremity arterial atherosclerosis. J Clin Epidemiol. 1997; 50:801-807. [PubMed: 9253391]

50. Bots ML, Dijk J M, Oren A, Grobbee DE. Carotid intima-media thickness, arterial stiffness and risk of cardiovascular disease: current evidence. J Hypertens. 2002; 20:2317-2325. [PubMed: 12473847]

51. Audelin MC, Genest J Jr. Homocysteine and cardiovascular disease in diabetes mellitus. Atherosclerosis. 2001; 159:497-511. [PubMed: 11730832]

52. Esposito K, Giugliano D, Nappo F, Marfella R. Campanian Postprandial Hyperglycemia Study Group. Regression of carotid atherosclerosis by control of postprandial hyper-glycemia in type 2 diabetes mellitus. Circulation. 2004; 110:214-219. [PubMed: 15197140]

53. Tarim E, Yigit F, Kilicdag E, et al. Early onset of subclinical atherosclerosis in women with gestational diabetes mellitus. Ultrasound Obstet Gynecol. 2006; 27:177-182. [PubMed: 16435313]

54. Xiang AH, Peters RK, Kjos SL, et al. Effect of thiazolidinedione treatment on progression of subclinical atherosclerosis in premenopausal women at high risk for type 2 diabetes. J Clin Endocrinol Metab. 2005; 90:1986-1991. [PubMed: 15623809]

55. Xiang AH, Hodis HN, Kawakubo M, et al. Effect of pioglitazone on progression of subclinical atherosclerosis in non-diabetic premenopausal Hispanic women with prior gestational diabetes. Atherosclerosis. 2008; 199:207-214. [PubMed: 18054942]

56. Pleiner J, Mittermayer F, Langenberger H, et al. Impaired vascular nitric oxide bioactivity in women with previous gestational diabetes. Wien Klin Wochenschr. 2007; 119:483-489. [PubMed: 17721768]

57. Mittermayer F, Mayer BX, Meyer A, et al. Circulating concentrations of asymmetrical dimethyl-Larginine are increased in women with previous gestational diabetes. Diabetologia. 2002; 45:13721378. [PubMed: 12378377]

58. von Mandach U, Lauth D, Huch R. Maternal and fetal nitric oxide production in normal and abnormal pregnancy. J Matern Fetal Neonatal Med. 2003; 13:22-27. [PubMed: 12710852]

59. Laakso M, Edelman SV, Brechtel G, Baron AD. Decreased effect of insulin to stimulate skeletal muscle blood flow in obese man. A novel mechanism for insulin resistance. J Clin Invest. 1990; 85:1844-1852. [PubMed: 2189893]

60. Mather KJ, Verma S, Anderson TJ. Improved endothelial function with metformin in type 2 diabetes mellitus. J Am Coli Cardiol. 2001; 37:1344-1350.

61. Watanabe Y, Sunayama S, Shimada K, et al. Troglitazone improves endothelial dysfunction in patients with insulin resistance. J Atheroscler Thromb. 2000; 7:159-163. [PubMed: 11480457]

62. Creager MA, Lüscher TF, Cosentino F, Beckman JA. Diabetes and vascular disease: pathophysiology, clinical consequences, and medical therapy: part I. Circulation. 2003; 108:15271532. [PubMed: 14504252]

63. Kautzky-Willer A, Fasching P, Jilma B, Waldhäusl W, Wagner OF. Persistent elevation and metabolic dependence of circulating E-selectin after delivery in women with gestational diabetes mellitus. J Clin Endocrinol Metab. 1997; 82:4117-4121. [PubMed: 9398724]

64. Bo S, Valpreda S, Menato G, et al. Should we consider gestational diabetes a vascular risk factor? Atherosclerosis. 2007; 194:e72-e79. [PubMed: 17055515]

65. Heitritter SM, Solomon CG, Mitchell GF, Skali-Ounis N, Seely EW. Subclinical inflammation and vascular dysfunction in women with previous gestational diabetes mellitus. J Clin Endocrinol Metab. 2005; 90:3983-3988. [PubMed: 15840749]

66. Di Benedetto A, Russo GT, Corrado F, et al. Inflammatory markers in women with a recent history of gestational diabetes mellitus. J Endocrinol Invest. 2005; 28:34-38. [PubMed: 15816369]

67. Qiu C, Sorensen TK, Luthy DA, Williams MA. A prospective study of maternal serum C-reactive protein (CRP) concentrations and risk of gestational diabetes mellitus. Paediatr Perinat Epidemiol. 2004; 18:377-384. [PubMed: 15367325]

68. Retnakaran R, Hanley AJ, Raif N, Connelly PW, Sermer M, Zinman B. C-reactive protein and gestational diabetes: the central role of maternal obesity. J Clin Endocrinol Metab. 2003; 88:35073512. [PubMed: 12915627] 
69. Gasic S, Winzer Ch, Bayerle-Eder M, Roden A, Pacini G, Kautzky-Willer A. Impaired cardiac autonomic function in women with prior gestational diabetes mellitus. Eur J Clin Invest. 2007; 37:42-47. [PubMed: 17181566]

70. Kenényi Z, Stella P, Nádasdi A, Tabák AG, Tamás G. Association between cardiovascular autonomic neuropathy and multimetabolic syndrome in a special cohort of women with prior gestational diabetes mellitus. Diabet Med. 1999; 16:794-795. [PubMed: 10510961]

71. Raffel LJ, Robbins DC, Norris JM, et al. The GENNID Study. A resource for mapping the genes that cause NIDDM. Diabetes Care. 1996; 19:864-872. [PubMed: 8842605]

72. Shah BR, Retnakaran R, Booth GL. Increased risk of cardiovascular disease in young women following gestational diabetes mellitus. Diabetes Care. 2008; 31:1668-1669. [PubMed: 18487472]

73. Freire CM, Nunes Mdo C, Barbosa MM, et al. Gestational diabetes: a condition of early diastolic abnormalities in young women. J Am Soc Echocardiogr. 2006; 19:1251-1256. [PubMed: 17000364]

74. Bendey-Lewis R, Levkoff S, Stuebe A, Seely EW. Gestational diabetes mellitus: postpartum opportunities for the diagnosis and prevention of type 2 diabetes mellitus. Nat Clin Pract Endocrinol Metab. 2008; 4:552-558. [PubMed: 18779843] 


\title{
Table 1
}

\section{Parameters Examined in GDM}

\author{
Cardiovascular Disease Risk Factors \\ - Type 2 diabetes mellitus \\ - Blood pressure \\ - Lipid profile \\ - Metabolic syndrome \\ Cardiovascular Disease Surrogate Measures \\ - Endothelial Dysfunction \\ $\bigcirc$ Brachial artery flow-mediated vasodilation \\ $\bigcirc$ Carotid artery intimal-medial thickness \\ - Biochemical Markers \\ O E-selectin \\ O Vascular adhesion molecule-1 \\ O Intercellular adhesion molecule-1 \\ - Inflammatory Markers \\ O C-reactive protein \\ O Fibrinogen \\ O Plasminogen activator inhibitor-1 \\ - Autonomic Dysfunction \\ $\bigcirc$ Heart rate variability \\ Cardiovascular Disease Manifestations \\ - Coronary Artery Disease and Cardiovascular Events \\ - Cardiac Dysfunction \\ O Tissue Doppler parameters \\ - Diastolic velocity \\ O Two-dimensional M-mode echocardiography
}

- Left ventricular mass 